\title{
THE COMPUTING PROFESSION IN THE ERA OF VIRTUAL ORGANISING
}

\author{
Ruud van Dael ${ }^{1}$ and Carolien Metselaar ${ }^{2}$ \\ 1) University of Nijmegen, The Netherlands \\ 2) University of Amsterdam, The Netherlands
}

\begin{abstract}
This paper discusses the professionalisation process of the computing profession which has entered a new phase triggered by the emerging concept of virtual organising. We start by describing the professionalisation process as a competition for tasks, this competition is illustrated by the history of the computing profession in the Netherlands. We distinguish three opportunities for the computing profession resulting from the emerging concept of virtual organising: first, the growing complexity of information and communication technology (ICT) combined with increasing dependency on this technology; second, the merging of knowledge of ICT with knowledge of a specific domain; and third, the intertwining of technological and organisational choices on the strategic level.
\end{abstract}

\section{INTRODUCTION}

Advanced information and communication technologies (ICT) create possibilities for new ways of organising by bridging space and time more easily and at lower costs. This means that most organisations will turn into virtual organisations. The introduction of these organisational forms means a new impetus for the professionalisation process of the computing professional. However, the question is whether the profession is willing and able to adapt quickly enough to the era of virtual organising.

To answer this question we will first introduce a sociological view on professionalisation processes in general. We will illustrate these processes by looking at the history of the computing profession in the Netherlands. In section three we will introduce the concept of virtual organising and discuss its consequences for the computing profession.

\section{PROFESSIONALISATION}

The terms 'professionalisation', 'profession' and 'professional' have a dual character (Mock 1973). Professions are related to the division of labour, and hence also to the division of tasks, some of which are performed by members of a particular profession. The same is true of an occupation. Usually members of a society intuitively know the difference between an 
occupation and a profession. Everybody who works has an occupation. Most people with an occupation would like to be members of a profession. To reach this professional status an occupation starts to professionalise. On the one hand this process of professionalisation is driven by the desire of people with an occupation to be seen as professionals. Professionalism is a status one sets out to acquire, not one which reflects some essential quality one has demonstrated. However, on the other hand, acquiring a professional status is closely related to the tasks carried out by the individual workers. Some tasks are better suited for professional status than others. Thus professionalism is also dependent upon the tasks performed (Shapiro 1994). The above reflects the dual character of the word profession. A profession ${ }^{1}$ is an occupation striving for more power (Johnson 1972). In the next section we discuss the process of professionalisation in which the power to perform tasks is competed for.

\subsection{Interprofessional competition}

The relation between a profession and its tasks is called jurisdiction. Claiming jurisdiction over tasks is an essential element in the process of professionalisation. Jurisdiction over certain tasks is not the input of the process, but rather the output. There is no natural division of tasks between professions. A profession has to compete with other professions for jurisdiction. As jurisdiction is exclusively earned by a particular profession, another profession cannot independently perform the same tasks. The division of tasks between professions is dynamic. Sometimes professions reach a settlement on the division of tasks. As a result, part of the jurisdiction will be stable for a while. However, both internal and external forces can disturb such a truce. New tasks may be created, old tasks may disappear and other professions may claim existing tasks. A profession acts in an interprofessional system in which there is constant competition for tasks. The stronger the professional jurisdiction the better its position in this competition. 'Mature' professions do not exist. Competition is dynamic and it never finishes. Although once in a while a certain profession may have strong jurisdiction for a long time, it is never 'fixed'2 (Abbott 1988).

For example, in the field of computing there has been a settlement between the electrical engineer and the computing professional since the sixties ${ }^{3}$. The engineer builds the hardware and the computing professional creates the software to make the hardware work (Utrecht 1973). In the nineties this settlement still holds (Werkterrein Informatica 1997).

The central point of interprofessional competition is claiming jurisdiction over tasks, which is a social-cognitive process. The cognitive part of the process deals with the way tasks are claimed. The social part of the process is about the acceptance of claims by relevant others. In the following sections we will first discuss the cognitive part and then the social part. 


\subsection{The cognitive part of the professionalisation process}

The most important aspect of the cognitive part of the professionalisation process is defining a task in such a way that the relation between task and profession is obvious and natural. A task is defined by means of the professional knowledge system. A knowledge system is the cognitive foundation of a profession. It is a logically classified set of abstract notions. By defining it in terms of the professional knowledge system a task is described in such a way that it cannot be defined by knowledge systems of other professions.

To create a strong relation between tasks and profession the following three steps have to be taken: diagnosis, inference and treatment. Making a diagnosis means reducing a task to information that is relevant for the profession only. After reducing a task to a problem in terms of the professional knowledge system the professional analyses the problem. The analysis is carried out in accordance with the logical structure of the knowledge system 4 . This results in the prescription of a treatment. It is important that the client perceives the treatment as effective (Abbott 1988). To reinforce its professional status a profession will define the effects of its treatment in terms of its knowledge system.

The knowledge system is constructed by members of the profession (Krogt 1981). It offers the profession a cognitive foundation for claiming tasks. However, it is not a set of decision rules that can be changed at will. After all, members of a profession are convinced that they do their jobs in a respectable way. Moreover, they have embodied the knowledge system during many years of training and practice.

Knowledge systems are often formalised and can acquire the status of objective knowledge. As academic knowledge has an aura of objectivity from which professions profit, universities have played a major role in constructing these knowledge systems.

In the fifties, automation was introduced as a major improvement for the first time. Organisational problems were defined as administrative data processing problems to be solved with the help of automation. The Dutch organisation Heidemij 5 had had serious problems with its wages administration since the end of the Second World War. After automation was advocated as the solution, all parties involved supported the purchase of an IBM $650^{6}$ in 1956 (Hoorn 1997).

\subsection{The social part of the professionalisation process}

The social part of the professionalisation process implies that claims for jurisdiction have to be acknowledged by relevant others. This acknowledgement process takes place at three levels: the societal level, the 
organisational level and the individual level (Mock 1973). At each level different persons or groups have to accept the claims. The interaction between the levels influences the acceptance of a claim. We start at the organisational level.

At the organisational level the competition for jurisdiction is between groups, such as governmental organisations, client organisations, suppliers and other professions. Since tasks are claimed for every member of a profession, jurisdictional claims are general claims. Applying for legal recognition is such a general claim for jurisdiction. Legal arrangements like compulsory consultation or minimal licensing requirements guarantee strong jurisdiction (Krogt 1981). For example, in the seventies the Dutch computing science community attempted to persuade the government to legally acknowledge computing science as an academic discipline. The members of the community were convinced that the profession needed such legal recognition to prevent computing in the Netherlands from becoming obsolete (Academische Raad 1980).

Professions also claim tasks in other ways. For example, when in the public domain the public's favour is vied for, it is important to portray a profession as a unity and to create clarity about professional work. One way to achieve this is to unite the professionals in a professional society. If a profession presents itself with one voice in the public domain, relevant others are more willing to accept its claims for jurisdiction (Krogt 1981). The Dutch Computer Society (NGI) originated from a merger between the technicalscientific computer society and the administrative data processing society 7 in 1977 . The new society wanted to create unity and clarity by representing the whole field of computing.

There are other ways to be acknowledged in the public domain. In the 1920 s, pressure by Philips resulted in the possibility of receiving an academic degree in technical physics at Delft University of Technology. This shows that a strong sponsor can also support the jurisdictional claims of a profession (Johnson 1972, Nagtegaal 1988).

The second level where jurisdiction is claimed is the individual level. This is the level where the actual work is done; it is also called the workplace. The individual as a person claims jurisdiction over tasks. On this level the professionalisation process is very informal. Day-to-day contacts with colleagues ensure an informal atmosphere of cooperation which is reinforced by the fact that individual workers need each other to keep the organisation running. Thus specific circumstances can blur the boundaries between professions. On the individual level jurisdiction can be different for each member of a profession, since being a member of a profession is just one argument to claim individual jurisdiction over tasks (Abbott 1988).

To make successful claims in the public domain the profession needs a strong social structure. Such a strong structure is required because one definition of the profession must be used in interactions with relevant 
others. However, in the workplace a strong social structure is not always an advantage, since a well accepted definition of a profession can interfere with individual claims for jurisdiction.

The organisational and individual level interact with each other. In the sixties nobody knew what working with computers meant. To create clarity the Dutch foundation for administrative automation 8 published reports in which the different job descriptions of the new profession were defined. The institute attempted to create one image of the profession in the public domain. The job descriptions were based on research carried out in different organisations, at the workplace level. In each new report ${ }^{9}$ the number of job descriptions and the accompanying tasks increased. Individuals working in computing apparently had success in claiming new tasks. They were not bound by a strict definition of the profession. After generalisation, these successful claims for jurisdiction on the individual level were used to claim new jurisdiction in the public domain (Dael 1996).

The societal level is the third level where jurisdiction is claimed. The process at this level is called professionalisation without professions. At this level the process is about the societal perception of professional tasks. These tasks or problems have to be important for the public. Prospective clients have to think that they themselves are not able to solve these problems but that professionals are able to do so. The problems that are usually mentioned are physical health, mental welfare and safety. These are tasks which were and are valued highly in Western societies. Since in former times the physician, the clergyman, and the soldier took care of these important tasks, they gained professional status as a sign of societal appreciation. This appreciation applies to both the tasks and the way these are performed. The influence of a single profession on the societal value of a task itself is almost negligible. It is difficult for a single profession to prescribe what is important for a particular society. On the other hand, the members of a profession influence the way a task is fulfilled. So they should be careful not to lose societal appreciation due to poor professional practice (Abbott 1988, Mock 1973).

In the early eighties the Dutch Prosecution Counsel ${ }^{10}$ had serious organisational and financial problems. When the management asked for more money the government's reaction was negative. They said that "they should first stop using the goose quill" and that automation would solve all their problems (Engelenburg 1991). The great societal value of words like automation and computers has contributed to the success of the computing profession. Opinions differ as to whether the success was achieved thanks to the way computing professionals have carried out their tasks or in spite of this. 


\subsection{The competition for jurisdiction}

In the competition for jurisdiction a professional knowledge system plays a major role. A profession has to find the optimal level of abstraction in its knowledge system, in order to be able to claim a wide range of tasks and at the same time be able to make clear what its speciality is. An abstract knowledge system enables a profession to define a wide range of tasks in terms of its knowledge system. However, if the knowledge system is too abstract, the relation between diagnosis and treatment will be too hard to recognise. As a result the profession will lose reliability. The relation between profession and tasks, the jurisdiction, must remain obvious and natural to prospective clients. On the other hand, a certain amount of abstraction is necessary. If a profession's work is perceived as too mundane the claim for jurisdiction will not be honoured. Clients need to think they cannot solve the problem themselves.

There is no ultimate given level of abstraction in the knowledge system. If a profession wants more tasks the level of abstraction is increased. If other professions or circumstances change the knowledge system has to be adjusted to another optimal level (Abbott 1988).

To illustrate the changing level of abstraction we will discuss the changes in the knowledge system of the computing profession. In the early sixties the new computing profession had a simple knowledge system. Some administrative and technical-scientific tasks were defined in terms of automation and computers. The professionals defined their work as 'working with computers'. That was enough to claim jurisdiction. As the profession was concentrated in the computing centre, the borders of the profession were physically clear. Entrance into the heart of the centre, the computer, was only allowed to the members of the profession, who often wore white coats. 'Users' could hand in their punch cards at an office window. The Dutch organisation Heidemij even made a gallery so visitors could gaze with admiration at the magic machine, an IBM 36011. Card punch operators, mostly young women, were not allowed to enter the computing room, because they were not members of the profession (Nagtegaal 1988).

During the 1960s machine-independent programming languages and the chip increased the difference between hardware and software. The construction of hardware became part of the jurisdiction of the electrical engineer. The jurisdiction of the computing profession changed and became 'putting the computer to work'. This definition was interpreted in two different ways. Some professionals defined it as structured programming and other professionals defined it as information systems development. This resulted in a rift in the new profession. Ever since the software crisis, which was perceived as a problem caused by bad unstructured programming, there has been a strong movement stressing the importance of structured programming. This movement's view was that the art of programming was the heart of computing. At the same time systems development became a major item in computing. The SDM (Systems Development Methodology) 
method was created in the early 1970s (Wit 1994). In this area the opinion was that developing, introducing and implementing information systems in organisations was the heart of computing. The proponents of this view had learned by experience that it was difficult to make sure that automation was accepted in organisations. The discussion during the 1970s about academic education in computing science concentrated on these two views. The Dutch computing community was unable to agree on the content of the curriculum. 'Programming people' insisted on more mathematics, whereas 'information systems people' favoured more organisational courses (Christiaan Huygens Symposia 1978).

The computer left the computing centre due to the introduction of the personal computer. The PC was placed on the users' desks. As a reaction computing professionals left the computing centre. They followed the computer and appeared in other parts of the organisation. The phrase 'putting the computer to work' was no longer enough to claim jurisdiction over tasks. As many people had learned to work with the machine, it had become mundane. The reaction of the profession was to abstract the knowledge system to 'provision of information'. The members of the computing profession were looked upon as 'specialists of information' (Zijderveld 1991). In 1986, the Dutch Computer Society defined the 'provision of information' as the central activity of the profession. This definition was more abstract than the definition formulated in 1982 when the central activity was still concentrated at automated information systems'. By making the knowledge system more abstract the profession attempted to decrease the relevance of the computer for its jurisdictional claims (Dael 1996).

The end of the 1980s saw a widening of the scope of 'provision of information'. Information in the computing profession was about texts and numbers, usually called data. This was changed by the introduction of multimedia machines. Information is now an integration of data, image and sound. However, it is not only the computing profession that is interested in these new media. Other professions are interested as well. For example, the School for Communication Systems in the Dutch city of Utrecht is part of the Faculty of Communication and Journalism. Constructing intranet and Internet environments, the main part of what students learn, is defined as a natural part of communication science and journalism. The Faculty of Informatics does not agree with this definition. They argue that this subject belongs to computing science (Jong 1997).

Since the beginning of the 1990s the term 'communication' had been added to the knowledge system of the computing professional. This extension has been influenced by the spread of electronic networks. Next to 'provision of information', until recently the central activity in the computing profession, 'supporting communication' is becoming more and more important. The popularity of the abbreviation ICT rather than IT reflects this change. The Dutch Computer Society has recently changed its name into 'NGI, platform for ICT-professionals 12 . 


\section{COMPUTING PROFESSIONALS IN VIRTUAL ORGANISATIONS}

Thanks to advanced information and communication technologies (ICT) time and space can be bridged and activities can be organised in new ways. This has resulted in the concept of virtual organising. This concept will affect the work of all professions. The central role of ICT in virtual organising gives the computing profession a head start. Virtual organising offers the computing profession new opportunities for increasing its jurisdiction. Before describing the opportunities open to the computing profession we will discuss the concept of virtual organising.

\subsection{Virtual organising}

Virtual organising is a concept that stimulates a lot of new ideas and opinions: it is used for web enterprises, outsourcing, network companies, electronic companies, virtual teams and virtual offices. Virtual organisation is also applied to a lot of different fields. People have written on virtual classrooms, virtual libraries, virtual reality, virtual retailing, virtual democracies and virtual banking (Dael and Metselaar 1997).

Central in all these descriptions is the fact that activities are organised in new ways whereby time and distance are bridged by the application of ICT. We define the blurring of boundaries as the distinctive feature of virtual organising; boundaries within organisations, boundaries between organisations and boundaries between individually operating knowledge workers (Metselaar and Dael 1999).

The central role of ICT implies that technological choices become more important. Virtual organising implies the intertwining of organisational choices and technological choices. Campbell's four categories of virtual organisations underline this merger (Campbell 1997, Dael and Metselaar 1997, Mcloughlin and Jackson 1997). He distinguishes the internal virtual organisation, the stable virtual organisation, the dynamic virtual organisation and the agile organisation.

In the internal virtual organisation functional structures are converted into business units or autonomous groups. Task integration and multidisciplinary team work are central concepts here. The stable virtual organisation is an organisation that outsources parts of its non-core activities to a small number of reliable suppliers. A dynamic virtual organisation cooperates with a large number of organisations on an opportunistic and temporary basis. Cooperation takes place whenever opportunities occur in the marketplace. The agile organisation or web enterprise is a business established via the Internet. It is a temporary network of experts working in a specific field or on a certain topic, offering products or services in a world wide market. 
Each category is a specific instantiation of virtual organising. For each category a specific technology is required and vice versa: each technology also needs a matching organisational structure. Thus every instantiation of virtual organising is a sociotechnical configuration. First, groupware and intranet are used in virtual teams within organisations. Second, a stable network organisation will use network technology and Electronic Data Interchange. Third, a dynamic network organisation is supported by network technology and the Internet. And fourth, the World Wide Web is central to web enterprises. We illustrate the mutual relations between technological and organisational aspects of virtual organisations more extensively elsewhere (Metselaar and Dael 1999).

\subsection{The opportunities for the computing profession}

Virtual organising makes technological choices as important as organisational choices: these choices are inextricably linked and are to be considered as sociotechnical choices. In the social-cognitive process of professionalisation there are opportunities for the computing profession to increase its jurisdiction in the era of virtual organising. We distinguish three kinds of changes. First, the technological complexity of ICT needed for virtual organising increases. Second, the scope of the jurisdiction of the computing professional is becoming wider. Since virtual organising is applied in every area, the computing professional also becomes an expert in these areas. And third, due to the intertwining of technological and organisational choices, sociotechnical choices about virtual organising have to be made on the strategic level.

Technological complexity increases due to virtual organising. Demands made on information and communication technology will be much stronger. Networks have to be on the air 24 hours a day. A broken network implies a temporary state of coma for an organisation. The protection of data will become much harder. Since other organisations use the same networks, information systems of different organisations have to be separated logically by fire-walls. In virtual organising different partners will work together. To make these relationships work, exchangeability of data is needed. This requires technological standardisation. The history of the Dutch PICAlibrary system shows that it can take years before standardisation is achieved (Dael and Metselaar 1997). The control-function becomes more difficult since boundaries are often unclear both organisationally and technically. This growing complexity and increasing dependency on the technology increases the importance and status of the 'old-style' computing professional, the professional whose expertise is in 'hard software'. However, other professions are also looking for a piece of the cake. The control-function used to be part of the computing profession, nowadays the EDP-auditor is an accountant (Dael 1996).

The second change we distinguish is the possible broadening of the jurisdiction of the computing profession. The boundaries between 
professional knowledge systems also become blurred. For instance, facilitating tele-learning can be seen as both a computing and an educational task. It is not clear whether supporting interaction in a learning environment is a computing or an educational speciality. In other areas this overlap between knowledge of ICT and knowledge of a specific domain also occurs. Advising about virtual retailing requires knowledge from computing but also from logistics and marketing. Thanks to document retrieval systems the work of a computing professional and the work of an archivist are merging. The challenge for the computing profession is to create new boundaries that are as optimal as possible. Whether this means incorporating parts of other professions or withdrawing to the technological core business is unclear. However, in the era of virtual organising the intertwining of ICT and domain knowledge will continue to grow. This implies more work for the computing professional or more ICT knowledge for the professionals that are using ICT. In the field of tele-learning both patterns are evolving. For example, the Dutch branch of IBM has recently started a department called learning technologies. IBM developed the 'IBM global campus model'. This model creates a tele-learning environment for life long learning for individual IBM-employees. On the other hand, at the Dutch University of Twente it is possible to study educational science and technology. Graduates are educational professionals who are capable of designing multi-media learning technologies (Dael and Metselaar 1997).

The third change in the professionalisation process we distinguish, is a change occurring at the strategic level. As we noted before, in the era of virtual organising technological and organisational choices leading to a specific sociotechnical configuration of virtual organising are inextricably linked. If organisations are planning to go virtual the sociotechnical choices have to be made on the strategic level. Thorough knowledge of ICT is needed to make these far-reaching decisions. Thus, a strategic subject such as choosing the best sociotechnical design also becomes part of the jurisdiction of computing science. The computing professional is knocking at the boardroom doors. As the status of ICT advice is growing, other consulting professions are becoming interested. The traditional boardroom advisers, the accounting and management consulting firms, are establishing ICT departments. They, too, have noticed the growing importance of sociotechnical choices on the strategic level (Automatiseringsgids 1997).

The growing technological complexity, the blurring of the borders with other professions, and the growing importance of ICT on the strategic level offer the computing profession opportunities to increase its jurisdiction. The profession will be able to define some of these new tasks by means of a knowledge system based on information provision and supporting communication. However, to fully profit from the opportunities offered in the era of virtual organising a higher level of abstraction will be required for the knowledge system. For example, members of the computing profession could present themselves as experts in sociotechnical designs and implementations. In addition to the reconstruction of the knowledge system, this next step in the professionalisation process requires the acquisition of 
social acceptance by relevant others of the new claims of the computing profession.

Social acceptance has to be acquired with caution. The computing profession is bound by its past. It is still equated with computers . The growing complexity of ICT in conjunction with the growing dependency of organisations on this technology guarantees a lot of work in this area. It would be unwise to dispose of these tasks. The past, however, has also created the view that members of the computing profession are 'nerds' who are unable to deal with real organisational problems (Scheepmaker 1996). As a result, computing professionals claiming jurisdiction over tasks not clearly linked to the technology often provoke a let the cobbler stick to his last' reaction. The strategy is to define the new tasks in terms of information provision and support of communication and thus to appeal to the old expertise. In addition to this, computing professionals should stress that their diagnosis of the problems is complementary to problem definitions of other professionals. This means that the new task of managing the virtual organisation should be claimed with caution.

\section{NOTES}

1 Profession is a widely used and commonly accepted term in the United States and in Great Britain. In the Netherlands and other European mainland countries it is less accepted [16]. We will use the word profession since this paper is written in English.

2 Priests who had a strong jurisdiction for a long time but have now lost it in lots of societies, are a case in point.

3 The first computing pioneers built and programmed the machines themselves (interview Van der Poel, 24-10-1996).

$4 \quad$ The way different professions handle a very busy and noisy child can serve as a somewhat rigid example. The medical profession will define the child as hyper-active. Hyper-activity is a disease that can be cured. The child will be treated. The child's teacher will make her diagnosis in a very different way. She will discretely ask the child about the situation at home.

5 Heidemij was responsible for the infrastructural repair work after the Second World War. Heidemij employed thousands of workers all over the country who had to be paid every week.

6 This was the first commercially bought computer in the Netherlands to be used for administrative data processing. SHELL had bought a Ferranti for scientific calculating in 1954 (interview prof. R.J. Lunbeck, 22-1-1998).

7 The Dutch name for technical-scientific society was 'Nederlands Rekenmachine Genootschap' (NRMG). The Dutch name for the administrative data processing society was 'Genootschap voor Automatisering' (GvA).

8 The Dutch name of the institute for administrative automation was 'Stichting Studiecentrum voor Administratieve Automatisering' (SSAA).

9 The 'SSAA' published reports in 1963, 1967 en 1971 [6].

10 In Dutch: Her Openbaar Ministrie

11 Based on interviews with prof. R.J. Lunbeck (22-1-1998) and H. Huis in 't Veld (1-31996 \& 26-4-1996).

12 The name used to be 'Nederlands Genootschap voor Informatica', abbreviated to NGI. Now it is just NGI; the original name is no longer used in official documents. 


\section{REFERENCES}

Abbot, A. (1988) The system of professions. An essay on the division of expert labour. University of Chicago Press, Chicago and London.

Academische Raad (1980) Voorstel voor opneming van een studierichting informatica in het Academisch statuut, AR-374, Voorburg, 15 februari 1980.

Automatiseringsgids (1997) Themabijlage, 26 september 1997.

Campbell, A. (1997) Knowledge management in the virtual enterprise. In Jackson, P. and Wielen, J. van der (eds.) Proceedings of the Second International Workshop on telework: 'building actions on ideas'. WORC, Tilburg University, p.15-25.

Christiaan Huygens Symposia (1978) 'Kunnen Computers kwaad?' en 'De academische opleiding in de informatica', Wiskundige studievereniging Christiaan Huygens.

Dael, R. van (1996) De profilering van een groeiende professie, rapporten Wetenschap \& Samenleving 1996-1, KUN.

Dael, R. van, C. Metselaar (red.) (1997) De virtuele organisatie. Kluwer BedrijfsInformatie, Deventer.

Engelenburg, H. (1991) COMPAS, kampioen van het compromis. Automatisering, 23 oktober 1991.

Hoorn, T. van (1997) Automatisering bij de Administratie van de Heidemij, concept-rapport voor het project Geschiedenis van de Informatie Technologie in Nederland.

Jong, S. de (1997) Wildgroei in hbo-informatica. Computable, 30 mei 1997, p. 33-35.

Johnson, T. (1972) Professions and Power. Humanities.

Krogt, T. van der (1981) Professionalisering en collectieve macht. Een conceptueel kader, Vuga, Den Haag.

Mcloughlin, I., P. Jackson (1997) Organisational learing and virtual technologies: towards a research agenda. In Jackson, P. and Wielen, J. van der (eds.) Proceedings of the Second International Workshop on telework: 'building actions on ideas'. WORC, Tilburg University, p.37-53.

Metselaar, C. and R. Van Dael (1999) Organisations going virtual. AI \& Society 13 200-209.

Mock, A.L. (1973) Beroepen in actie. Bijdrage tot een beroepensociologie, Boom, Meppel.

Nagtegaal, H.K. e.a. (red.) (1988) 60 jaar studie voor natuurkundig ingenieur te Delft, Faculteit der Technische Natuurkunde, Delft.

Oost, E. van (1994) Nieuwe functies, nieuwe verschillen. Genderprocessen in de constructie van de nieuwe automatiseringsfuncties 1955-1970, WMW, Eburon, Delft.

Scheepmaker, B. (1996) Het kippenhok en de informatie architect. Informatie en Informatiebeleid 7(2) 84-89.

Shapiro, S. (1994) Boundaries and quandaries: establishing a professional context for IT. Information Technology \& People 7(1) 48-68.

Utrecht (1973) Leerplan voor het Hoger Informatica Onderwijs: Rapport van de Subcommissie voor Wiskunde en Informatica bij het Hoger Beroepsonderwijs, Instituut voor Ontwikkeling Wiskunde Onderwijs, Utrecht.. 
Wit, D. de (1994) The shaping of automation. Verloren, Hilversum.

Werkterrein Informatica (1997) Het VRI-model (versie 2). Vereniging van Register Informatici, September 1997.

Zijderveld, A.C. (1991) De samenleving als schouwspel, 2e herz. dr., Lemma, Utrecht. 